\title{
Recent Progress of Nanoscale Metal-Organic Frameworks in Cancer Theranostics and the Challenges of Their Clinical Application
}

This article was published in the following Dove Press journal: International Journal of Nanomedicine

\author{
Wenjie Sun' \\ Shuying $\mathrm{Li}^{\prime}$ \\ Guiliang Tang' \\ Yuan Luo' \\ Shijing Ma' \\ Shaoxing Sun' \\ Jiangbo Ren $\mathbb{D}^{2}$ \\ Yan Gong (iD $)^{2}$ \\ Conghua Xie $\mathbb{D}^{1,3,4}$ \\ 'Department of Radiation and Medical \\ Oncology, Zhongnan Hospital of Wuhan \\ University, Wuhan, People's Republic of \\ China; ${ }^{2}$ Department of Biological \\ Repositories, Zhongnan Hospital of \\ Wuhan University, Wuhan, People's \\ Republic of China; ${ }^{3}$ Hubei Key \\ Laboratory of Tumor Biological \\ Behaviors, Zhongnan Hospital of Wuhan \\ University, Wuhan, People's Republic of \\ China; ${ }^{4}$ Hubei Cancer Clinical Study \\ Center, Zhongnan Hospital of Wuhan \\ University, Wuhan, People's Republic of \\ China
}

\begin{abstract}
The growing incidence of cancer raises an urgent need to develop effective diagnostic and therapeutic strategies. With the rapid development of nanomedicine, nanoscale metal-organic frameworks (NMOFs) presented promising potential in various biomedical applications in the last 2 decades, especially in cancer theranostics. Due to the unique features of NMOFs, including structural diversities, enormous porosity, multifunctionality and biocompatibility, they have been widely used to deliver imaging contrast agents and therapeutic drugs. Moreover, multiple types of contrast agents, anti-cancer drugs and targeting ligands could be co-delivered through one single NMOF to enable combination therapy. Co-delivering system using NMOFs helped to avoid multidrug resistance, to reduce adverse effects, to achieve imaging-guided precise therapy and to enhance anti-cancer efficacy. This review summarized the recent research advances on the application of NMOFs in biomedical imaging and cancer treatments in the last few years. The current challenges that impeding their translation to clinical practices and the perspectives for their future applications were also highlighted and discussed.
\end{abstract}

Keywords: nanomedicine, theranostic platform, biomedical imaging, combination therapy, clinical translation

\section{Introduction}

The incidence of cancer is increasing rapidly and it is still one of the most devastating diseases threatening people's health. ${ }^{1}$ Therapeutic strategies, including surgical intervention, radiotherapy (RT), and chemotherapy, are routine methods of cancer treatment in the clinic. However, owing to poor effects, intolerably systemic toxicity and high risk of recurrence, traditional treatments often fail to meet the clinical needs. Thus, there is an urgent need for safer and more effective treatment strategies to improve the survival rate of cancer patients.

By integrating functions of diagnostics and therapeutics into a single system, cancer theranostics has attracted great attention in cancer research. ${ }^{2,3}$ With the rapid development of nanotechnology in the last 2 decades, nanoparticles have been used in cancer theranostics for more efficient early diagnoses and early therapies. ${ }^{4}$ Metal-organic frameworks (MOFs) are a series of crystalline hybrid materials composed of metal ions or clusters and organic ligands. ${ }^{5,6}$ Recently, MOFs were scaled down to the nanometer sizes, namely nanoscale MOFs (NMOFs). NMOFs combine many unique properties into a single loading and delivery system, including high loading capacities, compositional and structural tenability, controllable and sustained drug release,
Correspondence: Conghua Xie; Yan Gong Zhongnan Hospital of Wuhan University, 169 Donghu Road, Wuhan, Hubei 43007I, People's Republic of China Tel +86-27-678I2607; +86-27-6787|47। Fax +86-27-678I2892; +86-27-678II46I Email chxie_65@whu.edu.cn; yan.gong@whu.edu.cn 
excellent biocompatibility and intrinsic biodegradable. ${ }^{7,8}$ In addition, postsynthetic modification offers NMOFs more desired functionalities. ${ }^{9,10}$ Nanoscopic size of NMOFs enables them to accumulate at the tumor sites due to the enhanced permeability and retention (EPR) effect of tumors. $^{11}$ These unique features promote NMOFs' widely application in delivering imaging contrast agents and anticancer drugs as attractive theranostic platforms. ${ }^{12}$

Based on the different microenvironment between normal and tumor tissues, tumor-targeting NMOFs can be designed to reduce the damage to normal tissues. According to the EPR effect, NMOFs can be accumulated at tumor sites, which is passive targeting. ${ }^{13}$ On the other hand, active targeting can be achieved by adding targeting ligands on the surface of NMOFs. Recent researches demonstrated the successful fabrication of stimuli-responsive NMOF systems based on acidic $\mathrm{pH}$ conditions in tumor microenvironment ${ }^{14-16}$ and the overexpressed biomarkers in cancer cells, such as vascular endothelial growth factor $(\mathrm{VEGF})^{17}$ and folate reporter $(\mathrm{FR}) .^{18,19}$
As shown in Figure 1, this review summarized the studies on the diagnostic and therapeutic applications of NMOFs in the last 5 years. The implication of NMOFs in combination cancer therapies was especially emphasized. The remaining challenges and future directions of NMOFs translational studies were highlighted.

\section{Implication of NMOFs in Biomedical Imaging}

The rapid development of biomedical imaging has greatly facilitated the early detection of cancers. The metal ions or clusters on NMOFs make them promising candidates as contrast agents for biomedical imaging, such as magnetic resonance imaging (MRI), computed tomography (CT), positron emission tomography (PET), and optical imaging (OI). Compared with traditional small-molecule contrast agents that are restricted by nonspecific distribution and rapid pharmacokinetics, NMOFs-based contrast agents are easily functionalized. In addition, NMOFs can co-deliver multiple biomolecules at the same time, so they can be used for

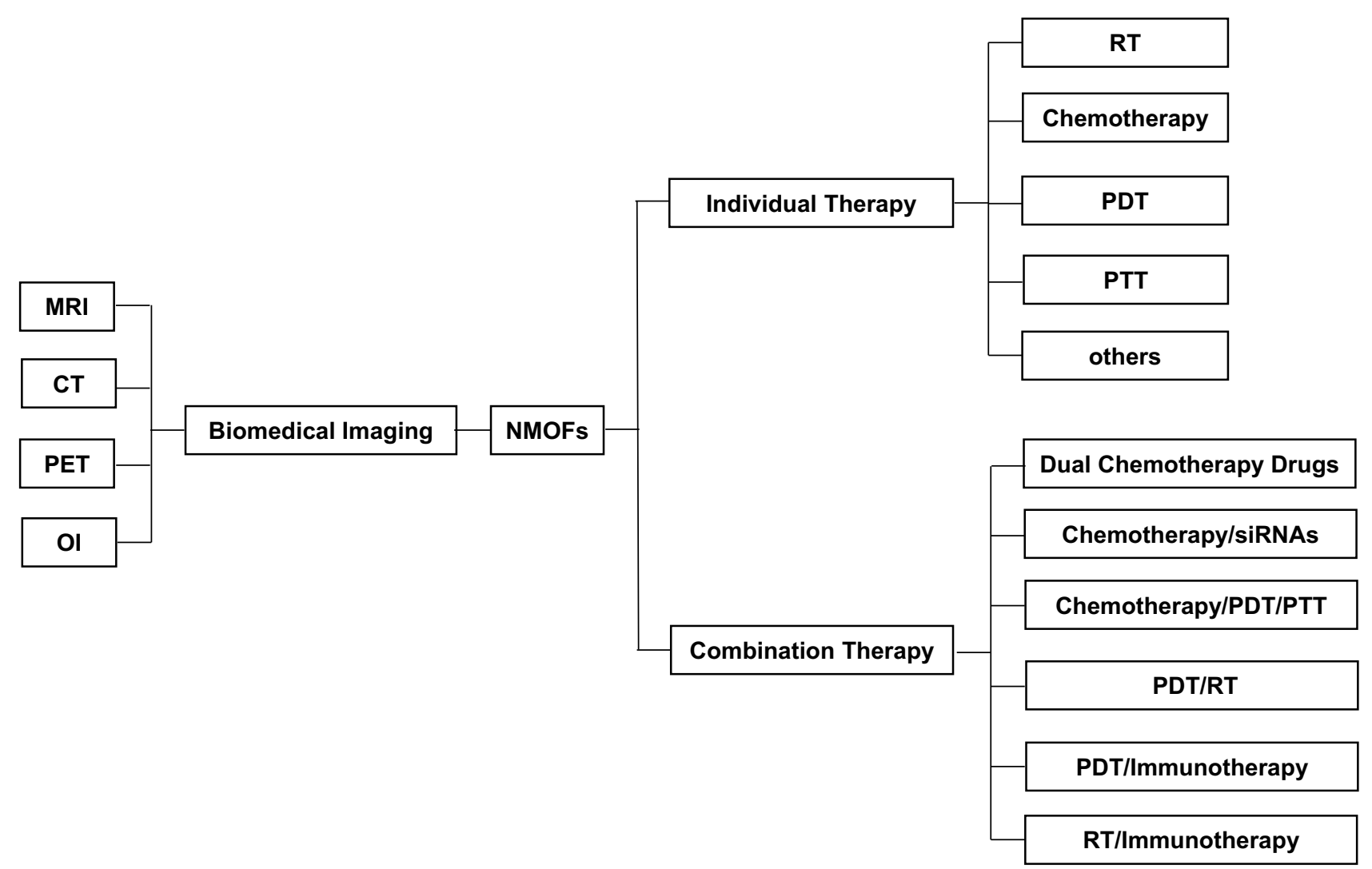

Figure I The applications of NMOFs in diagnostic and therapeutic strategies for cancers.

Abbreviations: MRI, magnetic resonance imaging; CT, computed tomography; PET, positron emission tomography; OI, optical imaging; NMOFs, nanoscale metal-organic frameworks; RT, radiotherapy; PDT, photodynamic therapy; PTT, photothermal therapy. 
multimodal imaging and image-guided therapy. The implication of NMOFs as imaging agents is illustrated in Table 1.

\section{MRI}

NMOFs have recently been used as potential MRI agents owing to their large metal payload, which greatly improved MRI quality and diagnostic sensitivity.

Lin's group ${ }^{36}$ reported the successful application of $\mathrm{Gd}^{3+}$ based NMOFs as MRI contrast agents for the first time in 2006. Long relaxation time of $\mathrm{Gd}^{3+}$ ensured the capability of MRI. In 2016, Wang et $\mathrm{al}^{20}$ synthesized a Gd and Eu codoped NMOF. By integrating $T_{1}$ and $T_{2}$ contrast agents into a nanoparticle, the Eu,Gd-NMOFs@ $\mathrm{SiO}_{2}$ simultaneously modulated $T_{1^{-}}$and $T_{2}$-weighted contrasts, suggesting their great potential as $T_{1}-T_{2}$ dual-modal imaging probes.

In recent years, researchers tried to synthesize stimuliresponsive MRI contrast agents to improve the sensitivity of early detection and to increase the efficacy of imaging-guided precision therapy. Ray and $\mathrm{Sahu}^{22}$ demonstrated that magnetic $\mathrm{Fe}_{3} \mathrm{O}_{4} @$ IRMOF-3/FA can function as strong $T_{2}$-weighted MRI contrast agents and delivery anti-cancer drug delivery agents at the same time. $\mathrm{Fe}_{3} \mathrm{O}_{4}$ were used to offer strong contrast in $T_{2}$-weighted MRI. FA conjugated to the NMOF

Table I The Applications of NMOFs in Biomedical Imaging

\begin{tabular}{|c|c|c|}
\hline NMOFs & $\begin{array}{l}\text { Imaging } \\
\text { Methods }\end{array}$ & References \\
\hline Eu,Gd-NMOF@SiO 2 & MRI & [20] \\
\hline Mn-IR825@PDA-PEG & MRI & [2I] \\
\hline $\mathrm{Fe}_{3} \mathrm{O}_{4} @ I R M O F-3 / F A$ & MRI & [22] \\
\hline $\left.\left.\mathrm{Mn}_{2}(\mathrm{Cmdcp})_{2}\left(\mathrm{H}_{2} \mathrm{O}\right)_{2}\right] \cdot \mathrm{H}_{2} \mathrm{O}\right\}_{\mathrm{n}}$ & MRI & [23] \\
\hline$\left.\left[\mathrm{Gd}(\mathrm{Cmdcp})\left(\mathrm{H}_{2} \mathrm{O}\right)_{3}\right]\left(\mathrm{NO}_{3}\right) \cdot 3 \mathrm{H}_{2} \mathrm{O}\right\}_{\mathrm{n}}$ & & \\
\hline MOF@HA@ICG NPs & MRI & [24] \\
\hline NMOF-SNO & MRI & [25] \\
\hline $\mathrm{Fe}_{3} \mathrm{O}_{4}$-ZIF-8 & MRI & [26] \\
\hline TPZ/Hf/TCPP/PEG & $\mathrm{CT}$ & [27] \\
\hline Au@MIL-88(Fe) & $\mathrm{MRI} / \mathrm{CT}$ & [28] \\
\hline DOX@Gd-MOFs-Glu & $\mathrm{MRI} / \mathrm{CT}$ & [29] \\
\hline${ }^{89} \mathrm{Zr}$-UiO-66/Py-PGA-PEG-F3 & PET & [30] \\
\hline $\mathrm{Fe}_{3} \mathrm{O}_{4} @ O C M C @ I R M O F-3 / F A$ & Ol & [3I] \\
\hline DOX@NPMOFs & Ol & [32] \\
\hline$[R s \subset n M O F-80 I]-G S /[R 6 G \subset n U i O-67]-G S$ & Ol & [33] \\
\hline UiO-66@DOPA-LB & $\mathrm{Ol}$ & [34] \\
\hline UCNP@Fe-MIL-I0I_NH ${ }_{2}$ & $\mathrm{MRI} / \mathrm{OI}$ & [35] \\
\hline
\end{tabular}

Abbreviations: MRI, magnetic resonance imaging; $\mathrm{CT}$, computed tomography; PET, positron emission tomography; OI, optical imaging; PDA, polydopamine; PEG, polyethylene glycol; FA, folate acid; HA, hyaluronic acid; ICG, indocyanine green; NPs, nanoparticles; SNO, S-nitrosothiol; TPZ, tirapazamine; TCPP, tetra (4-carboxyphenyl)porphine; Py-PGA-PEG, pyrene-derived polyethylene glycol; Glu, glucose; DOX, doxorubicin; OCMC, O-carboxymethyl chitosan; DOPA-LB, I,2dioleoyl-sn-glycero-3-phosphate lipid bilayer. surface served as the targeted reagent. Cell viability assays indicated that $\mathrm{Fe}_{3} \mathrm{O}_{4} @$ IRMOF-3/FA were nontoxic towards HeLa and NIH3T3 cells. Lin et $\mathrm{al}^{26}$ successfully synthesized $\mathrm{Fe}_{3} \mathrm{O}_{4}$-ZIF-8 as pH- and glutathione (GSH)-responsive MRI contrast agents due to acidic conditions and overexpressed $\mathrm{GSH}$ in the tumor microenvironment. The disassembled $\mathrm{Fe}_{3}$ $\mathrm{O}_{4}$-ZIF-8 released the $\mathrm{Fe}_{3} \mathrm{O}_{4}$ nanoparticles in tumor tissues, leading to transformation from $T_{2}$ to $T_{1}$ contrast enhancement, and providing a large inverse contrast compared with the $T_{2}$ contrast enhancement for normal tissues.

\section{CT}

Due to high spatial resolution, deep tissue penetration, and 3-dimensional (3D) visibility, CT has been found increasing use in the diagnosis and treatment of cancers in recent years. ${ }^{37}$ NMOFs served as contrast agents for CT imaging due to the incorporation of high $\mathrm{Z}$ element. ${ }^{38}$ Owing to the large X-ray absorption coefficient, gold nanoparticles were widely used as contrast agents for CT imaging. ${ }^{39,40}$ Shang et $\mathrm{al}^{28}$ synthesized small-scale core-shell nanoparticles, named as Au@MIL-88 (Fe). The modified nanocomposites possessed both CT enhancement ability and the $T_{2}$-weighted MRI property. Therefore, Au@MIL-88(Fe) served as multimodality imaging agents to integrate various image-enhancing behaviors into a single system for multimodality imaging. In addition, MTT assay showed that this nanoparticle had no significant cytotoxicity towards U87MG cells even at high concentrations. Liu et $\mathrm{al}^{27}$ also suggested that TPZ/Hf/TCPP/PEG acted as an efficient $\mathrm{CT}$ contrast agent due to the strong X-ray attenuation of Hf. In vivo CT imaging ability was validated in 4T1 tumorbearing mice.

\section{PET}

Compared with other imaging methods, PET imaging displays superior sensitivity, deeper tissue penetration capability, and better quantitative capacity, which made it widely used as diagnostic tools from preclinical to clinical research. ${ }^{41}$ The conventional PET imaging agent Fluorodeoxyglucose (FDG) hardly targets cancer cells specifically. Fortunately, this can be overcome by incorporated PET imaging agents into NMOFs. Chen et $\mathrm{al}^{30}$ designed and synthesized a radioactive

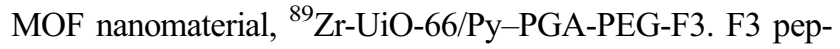
tide functioned as tumor-targeting ligand because it exhibited potent binding to tumor cells. In addition, the NMOFs showed a high loading capacity of DOX. This study suggested the potential of NMOFs for PET-guided tumor-targeted drugs delivery. In addition, in vivo safety evaluation confirmed that there was no observable acute, medium, or chronic toxicity. 


\section{Ol}

OI is increasingly applied to medical and biological research with its high resolution and high sensitivity. NMOFs have been widely used in OI due to their attractive water solubility. In 2016, Chowdhuri et $\mathrm{al}^{31}$ successfully designed a magnetic NMOF, Fe3O4@OCMC@IRMOF-3/ FA. Highly fluorescent carbon dots were conjugated on the surface of NMOFs for optical imaging and drug tracking. In 2017 , Liu et $\mathrm{al}^{32}$ validated that zirconium-porphyrin MOFs (NPMOFs) were an ideal OI-guided therapy system. Porphyrin provided strong fluorescence, but it was hydrophobic with a tendency to aggregate. NPMOFs helped to overcome these disadvantages and retained the photostability of the porphyrin. Ryu et $\mathrm{al}^{33}$ encapsulated dye molecules within pores of NMOFs and then found that Dye $\subset$ NMOFs could be successfully utilized for fluorescence imaging of human cells. More recently, Zhang et $\mathrm{al}^{34}$ reported that UiO-66@DOPA-LB exhibited improved biostability and prolonged circulation time, which endowed it great potential to serve as a nanocarrier for imaging agents. When labeling with NIR dye, IR-800, UiO-66@DOPA-LB-IR -800 exhibited superior capability for the detection of small tumor lesions at early stages.

\section{Implication of NMOFs in Individual Cancer Therapy}

A major reason for the failure of conventional cancer treatment is the inability of therapeutic drugs to be efficiently directed to tumor sites without damage to healthy tissues and organs. NOMFs not only improve the effects of traditional treatments such as RT and chemotherapy, but also benefit the newly development methods of phototherapy due to their excellent characteristics (Table 2).

\section{Implication of NMOFs in RT}

RT is a potent strategy to eliminate tumors. About half of cancer patients need at least one course of RT at different stages of treatment. ${ }^{65}$ However, traditional radiotherapeutic approaches lacked specificities to cancer cells and may trigger severe side effects. Therefore, it is of significant importance to explore effective methods to enhance the efficacy of RT in tumor tissues and reduce its adverse effects on normal tissues. NMOFs containing high$\mathrm{Z}$ elements showed promising potential to enhance RTinduced tumor fading due to their strong X-ray attenuation capabilities. ${ }^{66} \mathrm{Ni}$ et $\mathrm{al}^{42}$ reported that Hf-DBB-Ru served as a mitochondria-targeted NMOF for radiotherapy- radiodynamic therapy (RT-RDT). Hf-DBB-Ru exhibited strong mitochondria-targeting properties due to the presence of $\mathrm{Ru}(\mathrm{bpy})_{3}{ }^{2+}$. Upon irradiation with low doses of highly penetrating X-rays, Hf-DBB-Ru depolarized the mitochondrial membrane to initiate cancer cell apoptosis. In vivo study demonstrated that NMOF-enabled mitochondria-targeted RT-RDT led to obvious regression of MC38/ CT26 xenograft tumors. More recently, Lan et al ${ }^{43}$ synthesized a multifarious radioenhancer by integrating three high-Z components $\left(\mathrm{Hf}_{12}, \mathrm{DBB}-\mathrm{Ir}\right.$ and $\left.\mathrm{W}_{18}\right)$ into one NMOF. Upon X-ray irradiation, $\mathrm{W}_{18} @ \mathrm{Hf}_{12}$-DBB-Ir showed superb anticancer efficacy on two murine colorectal adenocarcinoma models.

\section{Implication of NMOFs in Chemotherapy}

Low bioavailability, poor tumor specificity and intolerable systemic toxicity are main obstacles for the clinical practice of chemotherapy. ${ }^{67}$ To overcome these disadvantages, NMOFs were used as drug delivery platforms to specifically target tumor tissues and controllably release anti-cancer drugs. ${ }^{17,68,69}$ Several chemotherapeutic drugs successfully delivered by NMOFs in the last 2 decades, such as cisplatin, ${ }^{68}$ 5-fluorouracil (5-FU), ${ }^{47,69}$ Doxorubicin (DOX), ${ }^{31,48}$ paclitaxel. ${ }^{14,22}$

In 2016, Chowdhuri et al $^{31}$ synthesized a new series of hybrid magnetic NMOFs that combined cancer-targeted drug delivery/imaging, high DOX loading capacity, and pH-sensitive DOX release into one single system. FA encapsulation on the surface of IRMOF-3 specifically targeted folate-overexpressed cancer cells. Chitosan was used for controlled and $\mathrm{pH}$-responsive drug release. Carbon dots were used for optical bioimaging. The as-synthesized Fe3O4@OCMC@IRMOF-3/FA showed high DOX loading efficiency. In vitro cytotoxicity study showed that $\mathrm{Fe}_{3} \mathrm{O}_{4}$ @OCMC@IRMOF-3/FA without DOX were nontoxic towards both HeLa cancer cells and L929 normal cells. While DOX encapsulated $\mathrm{Fe}_{3} \mathrm{O}_{4} @ O C M C @ I R M O F-3 / F A$ caused toxicity toward both normal and cancer cells, toxicity was more prominent in cancer cells than in normal cells. In 2018, Chen et al $^{17}$ developed VEGF-induced DOX-loaded NMOFs to achieve specific killness of cancer cells. Overexpressed VEGF in cancer cells functioned as a gate to achieve controlled release of DOX. Apoptosis experiments revealed selective cytotoxicity of the DOXloaded NMOFs towards the MDA-MB-231 breast cancer cells.

Samui et $\mathrm{al}^{50}$ developed NMOFs as targeted drug carriers and biomedical imaging by a single step synthetic 
Table 2 The Examples of NMOFs in Individual Cancer Therapy

\begin{tabular}{|c|c|c|c|c|}
\hline $\begin{array}{l}\text { Therapy Strategies } \\
\text { RT-RDT }\end{array}$ & $\begin{array}{l}\text { NMOFs } \\
\text { Hf-DBB-Ru } \\
\text { W }_{18} @ \mathrm{Hf}_{12}-\mathrm{DBB}-\mathrm{Ir}\end{array}$ & $\begin{array}{l}\text { Cancer Cell Types } \\
\text { MC38/CT26 cells } \\
\text { MC38/CT26 cells }\end{array}$ & $\begin{array}{l}\text { Animal Models } \\
\text { Mice bearing MC } 38 / \mathrm{CT} 26 \text { tumors } \\
\text { Mice bearing MC } 38 / \mathrm{CT} 26 \text { tumors }\end{array}$ & $\begin{array}{l}\text { References } \\
{[42]} \\
{[43]}\end{array}$ \\
\hline Chemotherapy & $\begin{array}{l}\text { VEGF-responsive DOX-loaded NMOFs } \\
\mathrm{Fe}-\mathrm{MIL}-53-\mathrm{NH}_{2} \text {-FA-5-FAM/5-FU } \\
\mathrm{Fe}_{3} \mathrm{O}_{4} @ I R M O F-3 / F A \\
\text { DOX@Gd-MOFs-Glu } \\
{ }^{89} \mathrm{Zr}-U i O-66 / P y-P G A-P E G-F 3 \\
\mathrm{Fe}_{3} \mathrm{O}_{4} @ O C M C @ I R M O F-3 / F A \\
\mathrm{Fe}_{3} \mathrm{O}_{4} @ Z I F-8 \\
\text { UiO-66/UiO-67 } \\
\text { DOX@UiO-68-FA } \\
\text { UCNP@ZIF-8/FA } \\
\text { P@ZIF-8 } \\
\text { Cisplatin@NMOF-I/DOX@NMOF-I } \\
\mathrm{NH}_{2} \text {-MIL-53(AI) }\end{array}$ & $\begin{array}{l}\text { MDA-MB-23 I cells } \\
\text { MGC-803 cells } \\
\text { HeLa cells } \\
\text { HeLa cells } \\
\text { MDA-MB-23 I cells } \\
\text { HeLa cells } \\
\text { MCF-7 cells } \\
\text { U-87 MG/HSC-3 cells } \\
\text { HepG2 cells } \\
\text { HeLa cells } \\
\text { MDA-MB-23I cells } \\
\text { HeLa cells } \\
\text { HepG2 cells }\end{array}$ & $\begin{array}{l}\text { None } \\
\text { None } \\
\text { None } \\
\text { Mice bearing Hela tumors } \\
\text { Mice bearing MDA-MB-23I tumors } \\
\text { None } \\
\text { None } \\
\text { None } \\
\text { Mice bearing HepG2 tumors } \\
\text { None } \\
\text { None } \\
\text { None } \\
\text { None }\end{array}$ & $\begin{array}{l}{[17]} \\
{[19]} \\
{[22]} \\
{[29]} \\
{[30]} \\
{[31]} \\
{[44]} \\
{[45]} \\
{[46]} \\
{[47]} \\
{[48]} \\
{[49]} \\
{[50]}\end{array}$ \\
\hline PDT & $\begin{array}{l}\text { FA-PCN-224 } \\
\text { DBP-UiO } \\
\text { DBC-UiO } \\
\text { PS@MOF-FA } \\
\text { NP-I } \\
\text { (nUiO-67)-Ru(bPy) }{ }_{3}{ }^{2+} \mathrm{NPs} \\
\text { UiO-66-TPP-SH } \\
\text { ZnDTPP-I }{ }_{2} \subset U i O-66 \\
\text { PCN-224-Pt } \\
\text { MB@THA-NMOF-76@cRGD } \\
\text { Ti-TBP } \\
\text { Au@ZIF-8 } \\
\text { MOF QDs }\end{array}$ & $\begin{array}{l}\text { HeLa/A549 cells } \\
\text { SQ20B cells } \\
\text { CT26/HT29 cells } \\
\text { HeLa cells } \\
\text { HepG2/HCTII6 cells } \\
\text { A549 cells } \\
\text { HeLa cells } \\
\text { HepG2 cells } \\
\text { HeLa/4TI cells } \\
\text { A549 cells } \\
\text { CT26 cells } \\
\text { EMT-6 cells } \\
\text { HeLa cells }\end{array}$ & $\begin{array}{l}\text { None } \\
\text { Mice bearing SQ20B tumors } \\
\text { Mice bearing CT26/HT29 tumors } \\
\text { None } \\
\text { Mice bearing HCTII } 6 \text { tumors } \\
\text { None } \\
\text { None } \\
\text { None } \\
\text { Mice bearing H22 tumors } \\
\text { None } \\
\text { Mice bearing CT26 tumors } \\
\text { Mice bearing EMT-6 tumors } \\
\text { Mice bearing HeLa tumors }\end{array}$ & $\begin{array}{l}{[18]} \\
{[51]} \\
{[52]} \\
{[53]} \\
{[54]} \\
{[55]} \\
{[56]} \\
{[57]} \\
{[58]} \\
{[59]} \\
{[60]} \\
{[61]} \\
{[62]}\end{array}$ \\
\hline PTT & $\begin{array}{l}\text { Mn-IR825@PDA-PEG } \\
\text { MOF@HA@ICG NPs } \\
\text { UiO-66@PAN } \\
\text { THA@Eu-NMOF@Fe/TA }\end{array}$ & $\begin{array}{l}4 T I \text { cells } \\
\text { MCF-7 cells } \\
\text { CT26/HCTII6 cells } \\
\text { None }\end{array}$ & $\begin{array}{l}\text { Mice bearing } 4 \mathrm{TI} \text { tumors } \\
\text { Mice bearing MCF- } 7 \text { tumors } \\
\text { Mice bearing CT26 tumors } \\
\text { None }\end{array}$ & $\begin{array}{l}{[21]} \\
{[24]} \\
{[63]} \\
{[64]}\end{array}$ \\
\hline
\end{tabular}

Abbreviations: RT-RDT, radiotherapy-radiodynamic therapy; PDT, photodynamic therapy; PTT, photothermal therapy; DOX, doxorubicin; FA, folate acid; OCMC, O-carboxymethyl chitosan; 5-FAM, 5-carboxyfluorescein; 5-FU, fluorouracil; Py-PGA-PEG, pyrene-derived polyethylene glycol; Glu, glucose; PS, photosensitizer; NPs, nanoparticles; PCN, porous coordination network; TPP, tris(4-chlorophenyl)porphyrin; MB, methylene blue; HTHA, 4,4,4-trifluoro-I-(9-hexylcarbazol-3-yl)-I,3-butanedione; cRGD, cyclic Arg-Gly-Asp peptide; TBP, 5, 10,15,20-tetra(p-benzoato)porphyrin; PDA, polydopamine; PNA, polyaniline; HA, hyaluronic acid; ICG, indocyanine green.

procedure. Lactobionic acid (LA) is the ligand of asialoglycoprotein receptors overexpressing in hepatocellular cells. ${ }^{70}$ The LA-conjugated NMOFs performed as an effective targeting ligand towards HepG2 cells for drug delivery. The MTT assay revealed that the DOX-loaded LA-modified NMOFs showed greater cytotoxicity towards HepG2 cells compared to normal HEK cells. Zhang et al ${ }^{29}$ developed a novel strategy for the design of smart NMOFbased nanoplatforms for MRI-guided tumor-targeted precise chemotherapy. The glucose not only acted as a targeting ligand to glucose-transported proteins in cancer cells, but also endowed the NMOFs with a pH-responded release of DOX. The presence of $\mathrm{Gd}^{3+}$ ions ensured the MRI capability. Therefore, targeted MRI-guided $\mathrm{pH}-$ responded chemotherapy was achieved by NMOFs-Glu nanocomposites.

In conclusion, smart theranostic platforms that combine tumor targeting, stimuli-responded release of anticancer drugs can be achieved by NMOFs, thus to realize imaging-guided precise chemotherapy.

\section{Implication of NMOFs in Phototherapy}

Phototherapy is an effective anticancer intervention that relies on light activation of photoactive materials localized 
in tumors, and is commonly implemented in the forms of photodynamic therapy (PDT) and photothermal therapy (PTT). ${ }^{71}$ Photosensitizers (PSs) are required to enhance the efficacy and selectivity of phototherapy via more singlet oxygen $\left({ }^{1} \mathrm{O}_{2}\right)$ generation in PDT and photothermal responses in $\mathrm{PTT}^{72}$ In both cases, delivery of PSs to the tumor tissues is of significant importance.

\section{Implication of NMOFs in PDT}

PDT combines 3 components, namely PS, light source and oxygen, and has emerged as an attractive new method of tumor treatment. Upon irradiation, the excited PS transfers energy to the surrounding oxygen to generate reactive oxygen species (ROS), particularly ${ }^{1} \mathrm{O}_{2}$, resulting in cell death and tumor-specific immunity. ${ }^{71,73}$ PDT provides an effective local cancer treatment by eradicating malignant tumors without damages to the surrounding normal tissues. However, owing to the poor water solubility and light penetration depth of traditional PSs, the clinical application of PDT is potentially limited. Recently, photosensitive agent-based NMOFs were designed to enhance PDT. $^{51,52,61,74}$ Proper size and the micropore of NMOFs allowed high PS loadings without self-quenching, whereas the porous structures of NMOFs facilitated the diffusion of ROS, thus leading to improved efficacy in PDT. ${ }^{74}$

Lin's group reported the first successful synthesis of a porphyrin-based NMOF, DBP-UiO, as an efficient PS in PDT for resistant head and neck cancer. ${ }^{51}$ They further optimized the design of NMOF via reducing the porphyrin ligands to its chlorin counterpart and synthesized the first chlorin-based NMOF, DBC-UiO. The authors demonstrated the superior PDT efficacy of DBC-UiO over DBP$\mathrm{UiO}$ both in vitro and in vivo in 2 colon cancer models. ${ }^{52}$

In addition, Park et al $^{18}$ synthesized the sizecontrollable NMOF, PCN-224 to enhance PDT efficacy. This nanoparticle demonstrated active targeting property due to postsynthetic FA modification. Jia et al ${ }^{59}$ successfully synthesized the MB@THA-NMOF-76@cRGD, which achieved NIR-triggered targeting PDT. Modifying cRGD on the surface of MB@THA-NMOF -76 had better biocompatibility and targeted properties into cancer cells. Recently, Ma et $\mathrm{al}^{61}$ described the synthesis and characteristics of an oxygen self-supplied nanodelivery system with embedded AuNPs on the NMOF surface as a catalase-like nanozyme and encapsulating Chlorin e6(Ce6) inside as a PS. This powerful nanoplatform not only made full use of NMOFs to fully utilize the advantages of PSs, but also produced $\mathrm{O}_{2}$ in a more effective way to relieve tumor hypoxia.

\section{Implication of NMOFs in PTT}

PTT causes thermal ablation and death of tumor cells with photoabsorbing agents to generate heat from light activation, preferably near-infrared (NIR) light. $^{75}$ It was recognized as a safe method to reduce the normal tissue damage and system adverse effects. The widely used PTT agents, such as inorganic gold nanomaterials and nanorods, are nonbiodegradable and have the potential for long-term toxicity. NMOFs-based PTT agents are biodegradable, exhibiting high tumor-homing ability and strong NIR absorption coefficients.

Wang et $\mathrm{al}^{63}$ synthesized polymer MOF hybrids, UiO66@PAN, which not only indicated significant photothermal therapeutic effect in vitro, but also effectively inhibited the growth of colon cancers in vivo. Cai et $\mathrm{al}^{24}$ synthesized a multifunctional nanoplatform for imaging-guided, anticancer PTT. Hyaluronic acid (HA) was conjugated to the MOF nanoparticles to target tumor cells. Indocyanine green (ICG), was incorporated function as NIR organic dye. And the $\mathrm{Fe}(\mathrm{III})$ ions in the MOF nanoparticles were utilized in $T_{2}$-weighted MRI. In vitro study showed that the MOF@HA@ICG nanoparticles exhibited strong NIR absorbance and low cytotoxicity. In vivo study indicated that the MOF@HA@ICG nanoparticles could accumulate at tumor sites due to their targeting capability and effectively inhibited the growth of MCF-7 xenograft tumors.

Yan et $\mathrm{al}^{64}$ designed and assembled a smart all-in-one nanoparticleTHA@Eu-NMOF@Fe/TA by postsynthetical functionalization of an $\mathrm{Eu}(\mathrm{III})$-based NMOF, which achieved precise temperature sensing and optical heating simultaneously. Fe/TA had PTT effects induced by $808 \mathrm{~nm}$ laser irradiation. The long emission lifetime and ultrasensitive transition of the $\mathrm{Eu}^{3+}$ endowed THA@Eu-NMOFs with the ability of real-time temperature sensing.

All these studies suggested PTT agents based on NMOFs significantly enhanced the lethal effects of PTT and reduce systemic side effects.

\section{Implication of NMOFs in Other Cancer Therapies \\ Nucleic Acid-Based Cancer Detection and Therapeutics}

NMOFs were used to deliver nucleic acids such as DNA, ${ }^{76}$ small interfering RNA (siRNA) ${ }^{68,77}$ and microRNA. ${ }^{78,79}$

Morris et $\mathrm{al}^{76}$ demonstrated that UiO-66- $\mathrm{N}_{3}$ NMOFs had the ability to deliver DNA to HeLa cells to achieve 
intracellular gene regulation. In addition, multiple research demonstrated that siRNA could be loaded by NMOFs to overcome multidrug resistance (MDR). ${ }^{68,77} \mathrm{Wu}$ et $\mathrm{al}^{79}$ developed NMOF-based strategies for multiplexed microRNA (miRNA) detection in living cancer cells for early diagnosis of cancer. Previous researches demonstrated that miRNA functioned as specific biomarkers on different kinds of cancer cells. ${ }^{80}$ For example, miRNA-2 1 is overexpressed in MCF-7 breast cancer cells, and miRNA-221 is overexpressed in OVCAR-3 ovarian cancer cells. ${ }^{81,82}$ Chen et al $^{78}$ designed miRNA-21- and miRNA221-responded DOX-loaded NMOFs for the treatment of breast cancer and ovarian cancer.

\section{Nitric Oxide (NO) Delivery}

Recently, free-radical gas NO has drawn widespread attention in cancer treatment. ${ }^{83,84}$ NMOFs have been reported for use in NO delivery due to suitable characteristics. ${ }^{85}$ Zhang et $\mathrm{al}^{25}$ developed a Mn-porphyrin NMOF platform as a novel theranostic system for MRI-guided controllable NO release and PTT synergetic therapy under single NIR irradiation. This platform showed effective tumor accumulation in vivo.

\section{Implication of NMOFs in Combination Cancer Therapy}

Generally, individual cancer therapy approach cannot eliminate tumor effectively. The combination of two or more therapeutic treatments has been considered as a promising cancer treatment strategy due to fewer side effects and synergistic anti-cancer efficacy. ${ }^{86}$ The realization of combination therapy based on NMOFs relied heavily on their multimodal loading capability. Recently, various types of therapeutic combinations, such as dual chemotherapy drugs, ${ }^{69}$ chemotherapy/siRNAs, ${ }^{68,77}$ chemotherapy/PDT, ${ }^{27,32}$ PDT/ immunotherapy ${ }^{87-90}$ or RT/immunotherapy ${ }^{91,92}$ based on NMOFs have been examined for tumor therapies both in vitro and in vivo (Table 3 ).

\section{Dual Chemotherapy Drugs}

Single chemotherapy drug always needs a high dose, which brings severe side effects. Zhang et $\mathrm{al}^{69}$ firstly established a co-delivery platform of 2 different chemical drugs based on nanoscale ZIF-90, which not only reduced the drug toxicity, but also achieved effective therapeutic synergy. Owing to high surface area and excellent biocompatibility, ZIF-90 was chosen as the framework of the

Table 3 The Examples of NMOFs in Combination Cancer Therapy

\begin{tabular}{|c|c|c|c|c|c|}
\hline \multicolumn{2}{|l|}{ Therapy Strategies } & \multirow{2}{*}{$\begin{array}{l}\text { NMOFs } \\
\text { 5-FU@ZIF-90-DOX }\end{array}$} & \multirow{2}{*}{$\begin{array}{l}\text { Cancer Cell Types } \\
\text { None }\end{array}$} & \multirow{2}{*}{$\begin{array}{l}\text { Animal Models } \\
\text { None }\end{array}$} & \multirow{2}{*}{$\begin{array}{l}\text { References } \\
{[69]}\end{array}$} \\
\hline Dual Chemo-drugs & 5-Fu/DOX & & & & \\
\hline Chemo/siRNAs & $\begin{array}{l}\text { Cisplatin/siRNAs } \\
\text { Paclitaxel/siRNAs }\end{array}$ & $\begin{array}{l}\text { siRNA/UiO-Cis } \\
\text { Se/Ru@MIL-IOI-(P+V)siRNA }\end{array}$ & $\begin{array}{l}\text { SKOV-3 cells } \\
\text { MCF-7/T cells }\end{array}$ & $\begin{array}{l}\text { None } \\
\text { Mice bearing MCF-7/T tumors }\end{array}$ & $\begin{array}{l}{[68]} \\
{[77]}\end{array}$ \\
\hline Chemo/PDT & $\begin{array}{l}\text { DOX/PDT } \\
\text { DOX/PDT } \\
\text { DOX/PDT } \\
\text { Tirapazamine/PDT } \\
\text { Banoxantrone/PDT }\end{array}$ & $\begin{array}{l}\text { DOX@NPMOFs } \\
\text { DOX/UCMOFs } \\
\text { NH2-MIL-I25/PEG } \\
\text { TPZ/Hf/TCPP/PEG } \\
\text { A@UiO-66-H-P }\end{array}$ & $\begin{array}{l}\text { HepG2 cells } \\
4 T I \text { cells } \\
\text { MCF-7 cells } \\
4 T I \text { cells } \\
\text { U87MG cells }\end{array}$ & $\begin{array}{l}\text { Mice bearing HepG2 tumors } \\
\text { Mice bearing } 4 \mathrm{TI} \text { tumors } \\
\text { None } \\
\text { Mice bearing } 4 \mathrm{TI} \text { tumors } \\
\text { Mice bearing U87MG tumors }\end{array}$ & $\begin{array}{l}{[32]} \\
{[93]} \\
{[94]} \\
{[27]} \\
{[95]}\end{array}$ \\
\hline Chemo/PTT & DOX/PTT & $\mathrm{Au} @ \mathrm{Cu}_{3}(\mathrm{BTC})_{2} \mathrm{NPs}$ & A549 cells & Mice bearing A549 tumors & [96] \\
\hline Chemo/PTT/PDT & СРT/PTT/PDT & AuNR@MOFs@CPT & 4TI cells & Mice bearing $4 \mathrm{TI}$ tumors & [97] \\
\hline $\mathrm{PTT} / \mathrm{NO}$ & & NMOF-SNO & MCF-7 cells & Mice bearing MCF-7/T tumors & [25] \\
\hline PDT/RT & & Hf-TCPP NMOF-PEG & 4TI cells & Mice bearing $4 \mathrm{TI}$ tumors & [66] \\
\hline PDT/Immunotherapy & $\begin{array}{l}\text { PDT/IDOi } \\
\text { PDT/ } \alpha \text { PD-I } \\
\text { PDT/ } / \alpha D-L I\end{array}$ & $\begin{array}{l}\text { IDOi@TBC-Hf } \\
\text { TBP-nMOF } \\
\text { Fe-TBP }\end{array}$ & $\begin{array}{l}\text { CT26/MC38 cells } \\
4 T 1 \text { cells } \\
\text { CT26 cells }\end{array}$ & $\begin{array}{l}\text { Mice bearing } \mathrm{CT} 26 / \mathrm{MC} 38 \text { tumors } \\
\text { Mice bearing } 4 \mathrm{TI} \text { tumors } \\
\text { Mice bearing } \mathrm{CT} 26 \text { tumors }\end{array}$ & $\begin{array}{l}{[88]} \\
{[89]} \\
{[87]}\end{array}$ \\
\hline RT/Immunotherapy & $\mathrm{RT} / \alpha \mathrm{PD}-\mathrm{LI}$ & $\mathrm{Hf}_{6}-\mathrm{DBA}$ and $\mathrm{Hf}_{12}-\mathrm{DBA}$ & CT26 cells & Mice bearing CT26 tumors & {$[91]$} \\
\hline
\end{tabular}

Abbreviations: RT-RDT, radiotherapy-radiodynamic therapy; PDT, photodynamic therapy; PTT, photothermal therapy; IDOi, Indoleamine 2.3-dioxygenase inhibitor; $\alpha$ PD-I, anti-programmed death-I; $\alpha$-PD-LI, anti-programmed death-ligand I; 5-FU, 5-fluorouracil; DOX, doxorubicin; NP,nanoparticles; PEG, polyethylene glycol; TPZ, tirapazamine; TCPP, tetra(4-carboxyphenyl)porphine; BTC, I,3,5-benzenetricarboxylate; CPT, camptothecin; SNO, S-Nitrosothiol; TCPP, tetra(4-carboxyphenyl)porphine; TBC, tetra( $p$-benzoato)chlorin; TBP, 5, 10,15,20-tetra( $p$-benzoato)porphyrin; DBA, 2.5-di( $p$-benzoato)aniline. 
NMOFs. This co-delivery system was generated by attaching DOX on the surface of nanoscale ZIF-90, while encapsulating 5-FU into the pores of the framework at the same time. Moreover, ZIF-90 exhibited more stability at high $\mathrm{pH}$, while at lower $\mathrm{pH}$, the framework of ZIF-90 was instable. Due to the acidic environment at tumor sites, 5-FU@ZIF-90-DOX could achieve cancer-targeted codelivery and controlled release of DOX and 5-Fu.

\section{Chemotherapy/siRNAs}

RNA interference (RNAi) is a sequence-specific and posttranscriptional gene silencing technique, which can be used to regulate protein expression and is currently used as a tool to modulate disease-related genes, such as MDR genes. ${ }^{98}$ Several studies have shown that silencing MDR genes using RNAi reversed cisplatin resistance in ovarian cancer cells. ${ }^{99-101}$ Several NMOFs have been developed to deliver chemotherapeutic drugs and siRNAs targeting MDR to chemo-resistant cancer cells to overcome MDR. ${ }^{68,77}$

$\mathrm{He}$ et $\mathrm{al}^{68}$ reported the first use of UiO NMOFs for the codelivery of cisplatin and pooled siRNAs to reverse MDR in ovarian cancer cells. Cisplatin prodrug was encapsulated into the pores of UiO, whereas pooled siRNAs binded to metal ions on the NMOFs surfaces. UiO protected siRNAs against nuclease degradation, and facilitated the siRNAs internalization to enhance the silencing efficiency of MDR genes. Chen et $\mathrm{al}^{77}$ used a similar strategy to utilize Se/Ru@MIL-101-(P+V) siRNA nanoparticles for pooled siRNAs delivery to overcome MDR in Taxol-resistant breast cancer cells. MIL-101 had a large surface area. Selenium (Se)-based complexes exhibited excellent anti-tumor effects and low systemic toxicity, ${ }^{102}$ and ruthenium $(\mathrm{Ru})$ anticancer drugs showed a remarkable antimetastatic activity. ${ }^{103}$ In vivo study indicated that Se@MIL101-(P+V)siRNA significantly suppressed cancer growth in MCF-7/T cells xenografts model.

\section{Chemotherapy/PDT or Chemotherapy/ PTT}

Several studies demonstrated that combining chemotherapy based on PDT potentially enhanced anticancer efficacy. ${ }^{27,95}$ The main obstacle of PDT is the hypoxia of tumor environment, which significantly limits its application. Therefore, relieving tissue hypoxia by NMOFs can be used to enhance the efficacy of PDT. Liu et $\mathrm{al}^{27}$ synthesized TPZ/Hf/TCPP/PEG with high loading capacity of the hypoxia-activated prodrug tirapazamine. This study demonstrated the potential of NMOF-based platforms to combine PDT and chemotherapy. More recently, He et al ${ }^{95}$ synthesized multifunctional A@UiO-66-H-P NMOFs, which also achieved a combination of NMOFs-based PDT with hypoxia-activated chemotherapy. In addition, due to the large surface area of A@UiO-66-H-P NMOFs and concentration gradient of phosphate between plasma and cells, efficient prodrug loading and controlled prodrug release can be realized.

The combination of chemotherapy with PTT also showed a synergistic anti-cancer effect. He et $\mathrm{al}^{96}$ manufactured multifunctional core-shell $\mathrm{Au} @ \mathrm{Cu}_{3}(\mathrm{BTC})_{2}$ nanoparticles, which showed both high DOX loading efficiency and excellent photothermal effect.

With the unique features of good biocompatibility and high sensitivity, Au nanoparticles were recognized as ideal materials of this NMOF. Due to good stability, low toxicity and strong NIR absorbance, $\mathrm{Cu}_{3}(\mathrm{BTC})_{2}$ was selected to enhance the photothermal effect. In vitro cytotoxicity studies revealed that even at a high concentration, $\mathrm{Au} @ \mathrm{Cu}_{3}(\mathrm{BTC})_{2}$ nanoparticles exhibited very low cytotoxicity on A549, beas-2b, MCF-7 and HeLa cells. In vivo study indicated that there were no obvious body weight losses of A549 xenograft model, suggesting its safety. This work inspired further researches on the invention of more multifunctional theranostic platforms based on NMOFs.

\section{PDT/RT}

Severe toxicity greatly limits the potential of RT. Combining RT with other therapeutic approaches has drawn great attention in the past few years, which significantly enhanced anticancer efficacy and decreased systemic toxicity. ${ }^{104,105}$ In 2016, Liu et al ${ }^{66}$ reported the successful synthesis of novel NMOFs that were used for the combination of PDT and RT in a murine breast cancer model. In this NMOFs platform, TCPP served as a PS of PDT, and $\mathrm{Hf}^{4+}$ with strong X-ray attenuation ability functioned as a radiosensitizer to enhance RT-induced tumor killing. In addition, these NMOFs showed tumor targeting due to the EPR effect. In vivo study indicated that the mice bearing $4 \mathrm{~T} 1$ tumors showed greatly tumor shrinking in the combined therapy group (i.v. injection with $\mathrm{NMOF-PEG} \mathrm{+} \mathrm{X-ray} \mathrm{+} \mathrm{Laser)} \mathrm{compared} \mathrm{with} \mathrm{respective}$ mono-therapies.

\section{PDT/Immunotherapy}

PDT can efficiently eliminate local tumors but is unable to control distant metastases. Immunotherapy, especially the application of immune checkpoint inhibitors, has achieved 
promising anti-cancer efficacy, but only worked for a few patients. It is also ineffective against poorly immunogenic tumors. $\mathrm{Lu}$ et $\mathrm{al}^{52}$ demonstrated that NMOF-mediated PDT induced immunogenic cell death, which endowed them with potential applications to enhance cancer immunotherapy. In recent years, there have been several studies about combining PDT and immunotherapy that elicited superb anticancer efficacy both in local and distant tumor in animal models. ${ }^{87-90}$

Indoleamine 2,3-dioxygenase (IDO) is an immune checkpoint. In 2016, Lu et $\mathrm{al}^{88}$ synthesized a chlorinbased nMOF, TBC-Hf, to load an IDO inhibitor (IDOi), which achieved an synergistic anti-cancer effect by combining NMOF-enabled PDT and immunotherapy. The combination therapy not only eliminated local tumors, but also achieved abscopal effects in breast and colorectal cancer mouse models. The mechanism study revealed an increased $\mathrm{T}$ cell infiltration in the tumor microenvironment after PDT treatment with IDOi@TBC-Hf. This study indicated the potential of NMOFs to enhance cancer immunotherapy. Similar strategies were also used to reduce primary and metastatic lung tumors. ${ }^{90}$
To overcome the hypoxia of tumor microenvironment, Lan et $\mathrm{al}^{87}$ synthesized NMOF to improve the PDTinduced immune response even under hypoxic conditions. Fe-TBP-based PDT significantly improved the efficacy of anti-programmed death-ligand 1 ( $\alpha$-PD-L1) treatment and elicited abscopal effects in a mouse model of colorectal cancer by recruiting both $\mathrm{CD} 4+$ and $\mathrm{CD} 8+$ cytotoxic $\mathrm{T}$ cells. Meanwhile, Zeng et $\mathrm{al}^{89}$ synthesized TBPNMOF, which can also function as a superb PS of PDT under hypoxic conditions. When combined with antiprogrammed death-1 ( $\alpha$ PD-1) antibody, abscopal effects were elicited.

\section{RT/Immunotherapy}

RT has the function of local immunomodulatory, which changes the microenvironment of irradiated tumors and synergizes with immune checkpoint blockade. $\mathrm{Ni}$ et $\mathrm{al}^{91}$ reported the design of Hf-based NMOFs, $\mathrm{Hf}_{6}$-DBA and $\mathrm{Hf}_{12}$-DBA, as highly effective radioenhancers, which combined NMOF-mediated RT and an $\alpha$-PD-L1 antibody, achieving local and distant rejection of colorectal tumors in mouse models. In addition, $\mathrm{Lu}$ et $\mathrm{al}^{92}$ described that

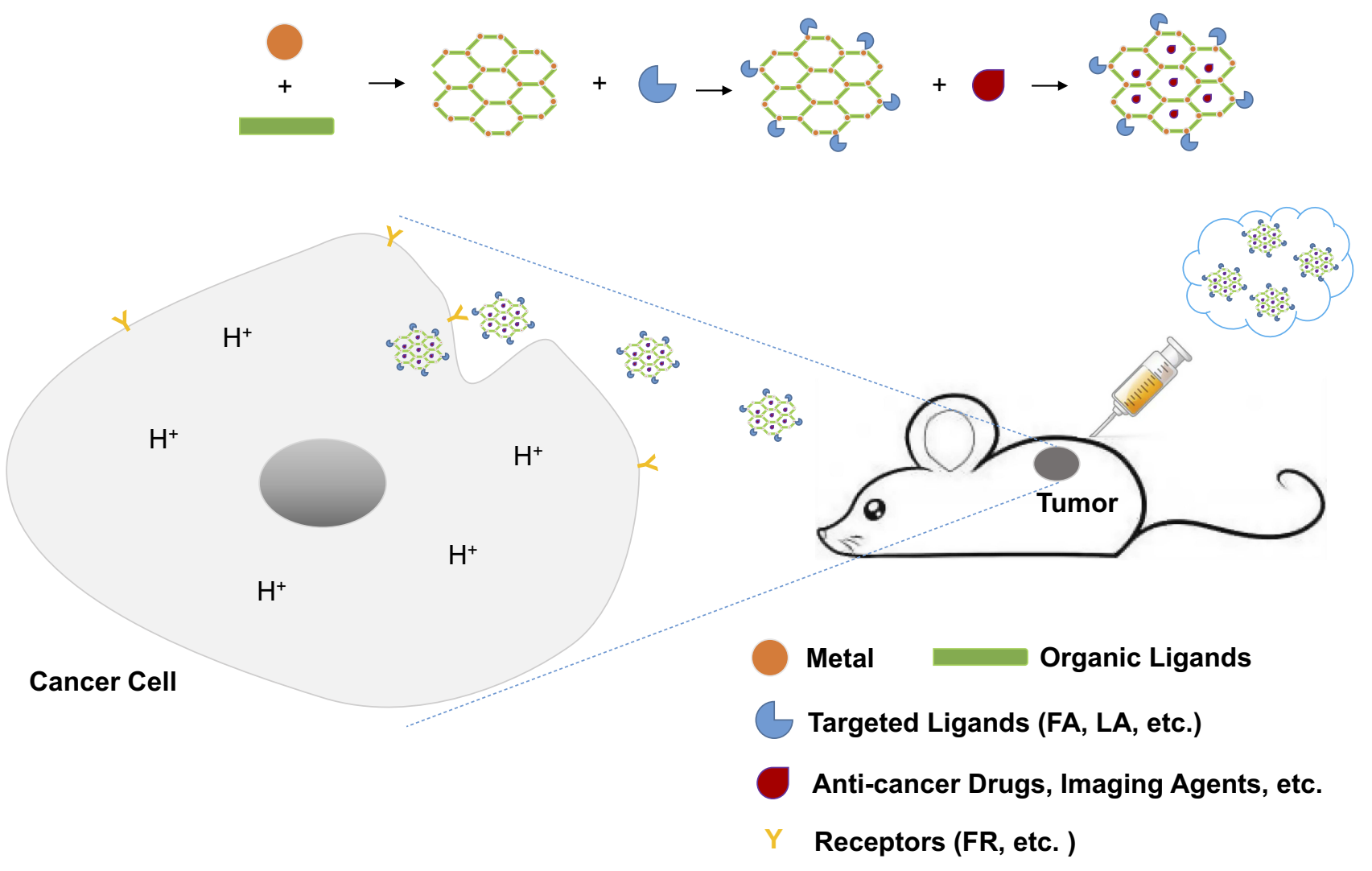

Figure 2 Schematic presentation of the synthesis and the implication of NMOFs in cancer theranostics.

Abbreviations: FA, folate acid; LA, lactobionic acid. 
combined NMOF-enabled RD-RDT therapy with IDOi both local and systemic tumors in mouse models of breast and colorectal cancer.

\section{Challenges of the Clinical Translation of NMOFs}

By combining both biomedicine imaging agents and anticancer drugs in a single NMOF platform, we can achieve both diagnosis and therapy of cancers at the same time. Due to passive targeting and active targeting of NMOFs, imaging agents and therapeutic drugs can accumulate at the tumor sites. Controlled and sustained drug delivery can be realized due to the existence of stimuli-responsive NMOFs. In addition, many surface modification approaches, such as PEG modification, have been employed, which improved the stability and long-circulating property of NMOFs efficiently. Moreover, combined therapeutic strategies based on NMOFs substantially enhanced the anti-tumor effect (Table 3), and researchers highly valued the importance of in vivo study. Figure 2 presents the schematic of the synthesis and the implication of NMOFs in cancer theranostics briefly.

Although significant progress has been made in the development of NMOFs for biomedical imaging and anti-cancer drug delivery, there were still some challenges which limit their translation to clinical settings. Firstly, the long-term toxicity and biosafety of NMOFs still need to be further evaluated. Although most NMOFs systems have no significant acute or subacute cytotoxicity in mice, but the long-term safety is to be examined. Secondly, there are significant differences between animal models and humans. Although many NMOFs platforms displayed efficient anti-cancer effects in animal models, its functions in the human body are still to be investigated. In addition, although targeted ligands can be incorporated into the NMOFs to realize tumor-targeted delivery of imaging agents and anticancer drugs, it is still quite difficult to distinguish cancerous and normal cells. Moreover, the construction of NMOFs systems often involves complex chemical synthesis and post-modifications Further studies are required to fully validate the implication of NMOFs at the clinical translation stage.

Given recent technical advancements over the last decades, smart and targeted NMOFs as cancer theranostic platforms will be further improved to enhance anticancer effects and better life quality for cancer patients.

\section{Acknowledgments}

This study was supported by National Natural Science Foundation of China (grant numbers 81372498, 81572967, 81773236, and 81800429); National Project for Improving the Ability of Diagnosis and Treatment of Difficult Diseases, National Key Clinical Speciality Construction Program of China (grant number [2013]544); the Fundamental Research Funds for the Central Universities (grant numbers 2042018kf0065 and 2042018kf1037); Health Commission of Hubei Province Scientific Research Project (grant numbers WJ2019H002 and WJ2019Q047); Wuhan City Huanghe Talents Plan, and Zhongnan Hospital of Wuhan University Science, Technology and Innovation Seed Fund (grant numbers znpy2016050, znpy2017001, znpy2017049, and znpy2018028).

\section{Disclosure}

The authors report no conflicts of interest in this work.

\section{References}

1. Siegel RL, Miller KD, Jemal A. Cancer statistics, 2017. $C A$ Cancer J Clin. 2017;67(1):7-30. doi:10.3322/caac.21387

2. Zhao X, Yang CX, Chen LG, Yan XP. Dual-stimuli responsive and reversibly activatable theranostic nanoprobe for precision tumor-targeting and fluorescence-guided photothermal therapy. Nat Commun. 2017;8:14998. doi:10.1038/ncomms14998

3. Bai J, Jia X, Zhen W, Cheng W, Jiang X. A facile ion-doping strategy to regulate tumor microenvironments for enhanced multimodal tumor theranostics. J Am Chem Soc. 2018;140(1):106-109. doi: $10.1021 /$ jacs. $7 \mathrm{~b} 11114$

4. Ng KK, Lovell JF, Zheng G. Lipoprotein-inspired nanoparticles for cancer theranostics. Acc Chem Res. 2011;44(10):1105-1113. doi:10.1021/ar200017e

5. Cui Y, Li B, He H, Zhou W, Chen B, Qian G. Metal-organic frameworks as platforms for functional materials. Acc Chem Res. 2016;49(3):483-493. doi:10.1021/acs.accounts.5b00530

6. Della Rocca J, Liu D, Lin W. Nanoscale metal-organic frameworks for biomedical imaging and drug delivery. Acc Chem Res. 2011;44(10):957-968. doi:10.1021/ar200028a

7. He C, Liu D, Lin W. Nanomedicine applications of hybrid nanomaterials built from metal-ligand coordination bonds: nanoscale metal-organic frameworks and nanoscale coordination polymers. Chem Rev. 2015;115(19):11079-11108. doi:10.1021/ acs.chemrev.5b00125

8. Li S, Huo F. Metal-organic framework composites: from fundamentals to applications. Nanoscale. 2015;7(17):7482-7501. doi:10.1039/C5NR00518C

9. Wang Z, Cohen SM. Postsynthetic modification of metal-organic frameworks. Chem Soc Rev. 2009;38(5):1315-1329. doi:10.1039/ b802258p

10. Islamoglu T, Goswami S, Li Z, Howarth AJ, Farha OK, Hupp JT. Postsynthetic tuning of metal-organic frameworks for targeted applications. Acc Chem Res. 2017;50(4):805-813. doi:10.1021/ acs.accounts.6b00577

11. Sun T, Zhang YS, Pang B, Hyun DC, Yang M, Xia Y. Engineered nanoparticles for drug delivery in cancer therapy. Angew Chem Int Ed Engl. 2014;53(46):12320-12364. doi:10.1002/anie.201403036 
12. Lu K, Aung T, Guo N, Weichselbaum R, Lin W. nanoscale metal-organic frameworks for therapeutic, imaging, and sensing applications. Adv Mater. 2018;30(37):e1707634. doi:10.1002/ adma.v30.37

13. Chen F, Hong $\mathrm{H}$, Zhang $\mathrm{Y}$, et al. In vivo tumor targeting and image-guided drug delivery with antibody-conjugated, radiolabeled mesoporous silica nanoparticles. ACS Nano. 2013;7 (10):9027-9039. doi:10.1021/nn403617j

14. Chen W, Yu X, Cecconello A, Sohn YS, Nechushtai R, Willner I. Stimuli-responsive nucleic acid-functionalized metal-organic framework nanoparticles using $\mathrm{pH}$ - and metal-ion-dependent DNAzymes as locks. Chem Sci. 2017;8(8):5769-5780. doi:10.1039/C7SC01765K

15. Kahn JS, Freage L, Enkin N, Garcia MA, Willner I. Stimuliresponsive DNA-functionalized metal-organic frameworks (MOFs). Adv Mater. 2017;29(6). doi:10.1002/adma.201602782

16. Tan LL, Li H, Qiu YC, et al. Stimuli-responsive metal-organic frameworks gated by pillar[5]arene supramolecular switches. Chem Sci. 2015;6(3):1640-1644. doi:10.1039/C4SC03749A

17. Chen WH, Yang Sung S, Fadeev M, Cecconello A, Nechushtai R, Willner I. Targeted VEGF-triggered release of an anti-cancer drug from aptamer-functionalized metal-organic framework nanoparticles. Nanoscale. 2018;10(10):4650-4657. doi:10.1039/C8NR00193F

18. Park J, Jiang Q, Feng D, Mao L, Zhou HC. Size-controlled synthesis of porphyrinic metal-organic framework and functionalization for targeted photodynamic therapy. J Am Chem Soc. 2016;138(10):3518-3525. doi:10.1021/jacs.6b00007

19. Gao X, Zhai M, Guan W, Liu J, Liu Z, Damirin A. Controllable synthesis of a smart multifunctional nanoscale metal-organic framework for magnetic resonance/optical imaging and targeted drug delivery. ACS Appl Mater Interfaces. 2017;9(4):3455-3462. doi:10. 1021/acsami.6b14795

20. Wang GD, Chen H, Tang W, Lee D, Xie J. Gd and Eu Co-doped nanoscale metal-organic framework as a T1-T2 dual-modal contrast agent for magnetic resonance imaging. Tomography. 2016;2 (3):179-187.

21. Yang Y, Liu J, Liang C, et al. Nanoscale metal-organic particles with rapid clearance for magnetic resonance imaging-guided photothermal therapy. ACS Nano. 2016;10(2):2774-2781. doi:10. 1021/acsnano.5b07882

22. Ray BD, Sahu SK. Magnetic nanoscale metal organic frameworks for potential targeted anticancer drug delivery, imaging and as an MRI contrast agent. Dalton Trans. 2016;45(7):2963-2973. doi:10. 1039/C5DT03736K

23. Qin L, Sun ZY, Cheng K, et al. Zwitterionic manganese and gadolinium metal-organic frameworks as efficient contrast agents for in vivo magnetic resonance imaging. ACS Appl Mater Interfaces. 2017;9(47):41378-41386. doi:10.1021/acsami.7b09608

24. Cai W, Gao H, Chu C, et al. Engineering phototheranostic nanoscale metal-organic frameworks for multimodal imaging-guided cancer therapy. ACS Appl Mater Interfaces. 2017;9 (3):2040-2051. doi:10.1021/acsami.6b11579

25. Zhang H, Tian XT, Shang Y, Li YH, Yin XB. Theranostic Mn-porphyrin metal-organic frameworks for magnetic resonance imaging-guided nitric oxide and photothermal synergistic therapy. ACS Appl Mater Interfaces. 2018;10(34):28390-28398. doi:10. 1021/acsami.8b09680

26. Lin $\mathrm{J}$, Xin P, An L, et al. Fe3O4-ZIF-8 assemblies as $\mathrm{pH}$ and glutathione responsive $\mathrm{T} 2-\mathrm{T} 1$ switching magnetic resonance imaging contrast agent for sensitive tumor imaging in vivo. Chem Commun (Camb). 2019;55(4):478-481. doi:10.1039/C8CC08 943D

27. Liu M, Wang L, Zheng X, Liu S, Xie Z. Hypoxia-triggered nanoscale metal-organic frameworks for enhanced anticancer activity. ACS Appl Mater Interfaces. 2018;10(29):24638-24647. doi:10.1021/acsami.8b07570
28. Shang W, Zeng C, Du Y, et al. Core-Shell Gold Nanorod@Metal-organic framework nanoprobes for multimodality diagnosis of glioma. Adv Mater. 2017;29(3):1604381. doi:10. 1002/adma.v29.3

29. Zhang H, Shang Y, Li YH, Sun SK, Yin XB. Smart metal-organic framework-based nanoplatforms for imaging-guided precise chemotherapy. ACS Appl Mater Interfaces. 2019;11(2):1886-1895. doi:10.1021/acsami.8b19048

30. Chen D, Yang D, Dougherty CA, et al. In vivo targeting and positron emission tomography imaging of tumor with intrinsically radioactive metal-organic frameworks nanomaterials. ACS Nano. 2017;11(4):4315-4327. doi:10.1021/acsnano. $7 \mathrm{~b} 01530$

31. Chowdhuri AR, Singh T, Ghosh SK, Sahu SK. Carbon dots embedded magnetic nanoparticles@Chitosan@metal organic framework as a nanoprobe for $\mathrm{pH}$ sensitive targeted anticancer drug delivery. ACS Appl Mater Interfaces. 2016;8(26):16573-16583. doi:10.1021/acsami.6b03988

32. Liu W, Wang YM, Li YH, et al. Fluorescent imaging-guided chemotherapy-and-photodynamic dual therapy with nanoscale porphyrin metal-organic framework. Small. 2017;13(17).

33. Ryu U, Yoo J, Kwon W, Choi KM. Tailoring nanocrystalline metal-organic frameworks as fluorescent dye carriers for bioimaging. Inorg Chem. 2017;56(21):12859-12865. doi:10.1021/ acs.inorgchem.7b01684

34. Zhang R, Qiao C, Jia Q, et al. Highly stable and long-circulating metal-organic frameworks nanoprobes for sensitive tumor detection in vivo. Adv Healthc Mater. 2019;8(19):e1900761. doi:10.1002/ adhm.v8.19

35. Li Y, Tang J, He L, et al. Core-shell upconversion nanoparticle@metal-organic framework nanoprobes for luminescent/magnetic dual-mode targeted imaging. Adv Mater. 2015;27 (27):4075-4080. doi:10.1002/adma.201501779

36. Rieter WJ, Taylor KM, An H, Lin W, Lin W. Nanoscale metal-organic frameworks as potential multimodal contrast enhancing agents. J Am Chem Soc. 2006;128(28):9024-9025. doi:10.1021/ja0627444

37. Ju Y, Zhang H, Yu J, et al. Monodisperse Au-Fe2C Janus nanoparticles: an attractive multifunctional material for triple-modal imaging-guided tumor photothermal therapy. ACS Nano. 2017;11 (9):9239-9248. doi:10.1021/acsnano.7b04461

38. deKrafft KE, Xie Z, Cao G, et al. Iodinated nanoscale coordination polymers as potential contrast agents for computed tomography. Angew Chem Int Ed Engl. 2009;48(52):9901-9904. doi:10.1002/anie.v48:52

39. Kattumuri V, Katti K, Bhaskaran S, et al. Gum arabic as a phytochemical construct for the stabilization of gold nanoparticles: in vivo pharmacokinetics and X-ray-contrast-imaging studies. Small. 2007;3(2):333-341. doi:10.1002/(ISSN)16136829

40. Kim D, Park S, Lee JH, Jeong YY, Jon S. Antibiofouling polymer-coated gold nanoparticles as a contrast agent for in vivo X-ray computed tomography imaging. J Am Chem Soc. 2007;129(24):7661-7665. doi:10.1021/ja071471p

41. Hong $\mathrm{H}$, Chen F, Zhang Y, Cai W. New radiotracers for imaging of vascular targets in angiogenesis-related diseases. Adv Drug Deliv Rev. 2014;76:2-20. doi:10.1016/j.addr.2014. 07.011

42. Ni K, Lan G, Veroneau SS, Duan X, Song Y, Lin W. Nanoscale metal-organic frameworks for mitochondria-targeted radiotherapyradiodynamic therapy. Nat Commun. 2018a;9(1):4321. doi:10.1038/ s41467-018-06655-7

43. Lan G, Ni K, Veroneau SS, Luo T, You E, Lin W. Nanoscale metal-organic framework hierarchically combines high-Z comp onents for multifarious radio-enhancement. $J$ Am Chem Soc. 2019;141(17):6859-6863. doi:10.1021/jacs.9b03029 
44. Zhuang J, Kuo CH, Chou LY, Liu DY, Weerapana E, Tsung CK. Optimized metal-organic-framework nanospheres for drug delivery: evaluation of small-molecule encapsulation. ACS Nano. 2014;8(3):2812-2819. doi:10.1021/nn406590q

45. Filippousi M, Turner S, Leus K, et al. Biocompatible Zr-based nanoscale MOFs coated with modified poly(epsilon-caprolactone) as anticancer drug carriers. Int J Pharm. 2016;509(1-2):208-218. doi:10.1016/j.jpharm.2016.05.048

46. Li Y, Zhao XD, Yin HP, Chen GJ, Yang S, Dong YB. A drug-loaded nanoscale metal-organic framework with a tumor targeting agent for highly effective hepatoma therapy. Chem Commun (Camb). 2016;52 (98):14113-14116. doi:10.1039/C6CC07321B

47. Chowdhuri AR, Laha D, Pal S, Karmakar P, Sahu SK. One-pot synthesis of folic acid encapsulated upconversion nanoscale metal organic frameworks for targeting, imaging and $\mathrm{pH}$ responsive drug release. Dalton Trans. 2016;45(45):18120-18132. doi:10.10 39/C6DT03237K

48. Zhou W, Wang L, Li F, et al. Selenium-containing polymer@metal-organic frameworks nanocomposites as an efficient multiresponsive drug delivery system. Adv Funct Mater. 2017;27(6):1605465. doi:10.1002/adfm.201605465

49. Samanta D, Roy S, Sasmal R, et al. Solvent adaptive dynamic metal-organic soft hybrid for imaging and biological delivery. Angew Chem Int Ed Engl. 2019;58(15):5008-5012. doi:10.1002/ anie. 201900692

50. Samui A, Pal K, Karmakar P, Sahu SK. In situ synthesized lactobionic acid conjugated NMOFs, a smart material for imaging and targeted drug delivery in hepatocellular carcinoma. Mater Sci Eng C Mater Biol Appl. 2019;98:772-781. doi:10.1016/j.msec.2019.01.032

51. Lu K, He C, Lin W. Nanoscale metal-organic framework for highly effective photodynamic therapy of resistant head and neck cancer. J Am Chem Soc. 2014;136(48):16712-16715. doi:10.1021/ja508679h

52. Lu K, He C, Lin W. A chlorin-based nanoscale metal-organic framework for photodynamic therapy of colon cancers. $J \mathrm{Am}$ Chem Soc. 2015;137(24):7600-7603. doi:10.1021/jacs.5b04069

53. Zhang L, Lei J, Ma F, Ling P, Liu J, Ju H. A porphyrin photosensitized metal-organic framework for cancer cell apoptosis and caspase responsive theranostics. Chem Commun (Camb). 2015;51 (54):10831-10834. doi:10.1039/C5CC03028E

54. Ma Y, Li X, Li A, Yang P, Zhang C, Tang B. H2 S-activable MOF nanoparticle photosensitizer for effective photodynamic therapy against cancer with controllable singlet-oxygen release. Angew Chem Int Ed Engl. 2017;56(44):13752-13756. doi:10.1002/ anie. 201708005

55. Chen R, Zhang J, Chelora J, et al. Ruthenium(II) complex incorporated UiO-67 metal-organic framework nanoparticles for enhanced two-photon fluorescence imaging and photodynamic cancer therapy. ACS Appl Mater Interfaces. 2017;9 (7):5699-5708. doi:10.1021/acsami.6b12469

56. Kan JL, Jiang Y, Xue A, et al. Surface decorated porphyrinic nanoscale metal-organic framework for photodynamic therapy. Inorg Chem. 2018;57(9):5420-5428. doi:10.1021/acs.inorgchem. $8 \mathrm{~b} 00384$

57. Zhou LL, Guan Q, Li YA, Zhou Y, Xin YB, Dong YB. One-pot synthetic approach toward porphyrinatozinc and heavy-atom involved $\mathrm{Zr}-\mathrm{NMOF}$ and its application in photodynamic therapy. Inorg Chem. 2018;57(6):3169-3176. doi:10.1021/acs.inorgchem. $7 \mathrm{~b} 03204$

58. Zhang Y, Wang F, Liu C, et al. Nanozyme decorated metal-organic frameworks for enhanced photodynamic therapy. ACS Nano. 2018;12(1):651-661. doi:10.1021/acsnano.7b07746

59. Jia J, Zhang Y, Zheng M, et al. Functionalized Eu(III)-based nanoscale metal-organic framework to achieve near-IR-triggered and -targeted two-photon absorption photodynamic therapy. Inorg Chem. 2018;57(1):300-310. doi:10.1021/acs.inorgchem.7b02475
60. Lan G, Ni K, Veroneau SS, et al. Titanium-based nanoscale metal-organic framework for type I photodynamic therapy. $\mathrm{J} \mathrm{Am}$ Chem Soc. 2019;141(10):4204-4208. doi:10.1021/jacs.8b13804

61. Ma YC, Zhu YH, Tang XF, et al. Au nanoparticles with enzyme-mimicking activity-ornamented ZIF-8 for highly efficient photodynamic therapy. Biomater Sci. 2019;7(7):2740-2748. doi:10.1039/C9BM00333A

62. Wang $\mathrm{H}, \mathrm{Yu} \mathrm{D}$, Fang $\mathrm{J}$, et al. Renal-clearable porphyrinic metal-organic framework nanodots for enhanced photodynamic therapy. ACS Nano. 2019;13(8):9206-9217. doi:10.1021/acsnano. 9b03531

63. Wang W, Wang L, Li Y, Liu S, Xie Z, Jing X. Nanoscale polymer metal-organic framework hybrids for effective photothermal therapy of colon cancers. Adv Mater. 2016;28(42):9320-9325. doi:10.1002/adma.201602997

64. Yan H, Ni H, Jia J, et al. Smart all-in-one thermometer-heater nanoprobe based on postsynthetical functionalization of a Eu(III)-metal-organic framework. Anal Chem. 2019;91 (8):5225-5234. doi:10.1021/acs.analchem. 8 b05960

65. Skliarenko J, Warde P. Practical and clinical applications of radiation therapy. Medicine. 2016;44(1):15-19. doi:10.1016/j. mpmed.2015.10.016

66. Liu J, Yang Y, Zhu W, et al. Nanoscale metal-organic frameworks for combined photodynamic \& radiation therapy in cancer treatment. Biomaterials. 2016;97:1-9. doi:10.1016/j.biomaterials.2016.04.034

67. Illes B, Wuttke S, Engelke H. Liposome-coated iron fumarate metal-organic framework nanoparticles for combination therapy. Nanomaterials. 2017;7(11):351. doi:10.3390/nano7110351

68. He C, Lu K, Liu D, Lin W. Nanoscale metal-organic frameworks for the co-delivery of cisplatin and pooled siRNAs to enhance therapeutic efficacy in drug-resistant ovarian cancer cells. $J \mathrm{Am}$ Chem Soc. 2014;136(14):5181-5184. doi:10.1021/ja4098862

69. Zhang FM, Dong H, Zhang X, et al. Postsynthetic modification of ZIF-90 for potential targeted codelivery of two anticancer drugs. ACS Appl Mater Interfaces. 2017;9(32):27332-27337. doi:10.10 21/acsami.7b08451

70. Zeng Y, Zhang D, Wu M, et al. Lipid-AuNPs@PDA nanohybrid for MRI/CT imaging and photothermal therapy of hepatocellular carcinoma. ACS Appl Mater Interfaces. 2014;6(16):14266-14277. doi:10.1021/am503583s

71. Dong Z, Feng L, Hao Y, et al. Synthesis of hollow biomineralized CaCO3-polydopamine nanoparticles for multimodal imaging-guided cancer photodynamic therapy with reduced skin photosensitivity. J Am Chem Soc. 2018;140(6):2165-2178. doi:10.1021/jacs.7b11036

72. Qiu WX, Liu LH, Li SY, Lei Q, Luo GF, Zhang XZ. ACPI conjugated gold nanorods as nanoplatform for dual image guided activatable photodynamic and photothermal combined therapy in vivo. Small. 2017;13(18). doi:10.1002/smll.201603956

73. Guo T, Wu Y, Lin Y, et al. Black phosphorus quantum dots with renal clearance property for efficient photodynamic therapy. Small. 2018;14(4).

74. Horcajada P, Gref R, Baati T, et al. Metal-organic frameworks in biomedicine. Chem Rev. 2012;112(2):1232-1268. doi:10.1021/ cr200256v

75. Cheng L, Wang C, Feng L, Yang K, Liu Z. Functional nanomaterials for phototherapies of cancer. Chem Rev. 2014;114 (21):10869-10939. doi:10.1021/cr400532z

76. Morris W, Briley WE, Auyeung E, Cabezas MD, Mirkin CA. Nucleic acid-metal organic framework (MOF) nanoparticle conjugates. $J \mathrm{Am}$ Chem Soc. 2014;136(20):7261-7264. doi:10.1021/ja503215w

77. Chen Q, Xu M, Zheng W, Xu T, Deng H, Liu J. Se/Ru-decorated porous metal-organic framework nanoparticles for the delivery of pooled sirnas to reversing multidrug resistance in taxol-resistant breast cancer cells. ACS Appl Mater Interfaces. 2017;9 (8):6712-6724. doi:10.1021/acsami.6b12792 
78. Chen W, Luo GF, Sohn YS, Nechushtai R, Willner I. miRNAspecific unlocking of drug-loaded metal-organic framework nanoparticles: targeted cytotoxicity toward cancer cells. Small. 2019;15(17):e1900935.

79. Wu Y, Han J, Xue P, Xu R, Kang Y. Nano metal-organic framework (NMOF)-based strategies for multiplexed microRNA detection in solution and living cancer cells. Nanoscale. 2015;7 (5):1753-1759. doi:10.1039/C4NR05447D

80. Di Leva G, Garofalo M, Croce CM. MicroRNAs in cancer. Annu Rev Pathol. 2014;9:287-314. doi:10.1146/annurev-pathol-012513104715

81. Heneghan HM, Miller N, Lowery AJ, Sweeney KJ, Kerin MJ. MicroRNAs as novel biomarkers for breast cancer. J Oncol. 2009;2009:950201

82. Hoheisel J, Dahiya N, Sherman-Baust CA, et al. MicroRNA expression and identification of putative miRNA targets in ovarian cancer. PLoS One. 2008;3(6):e2436. doi:10.1371/journal.pone.0002436

83. Fan W, Yung BC, Chen X. Stimuli-responsive NO release for on-demand gas-sensitized synergistic cancer therapy. Angew Chem Int Ed Engl. 2018;57(28):8383-8394. doi:10.1002/anie.v57.28

84. Mocellin S, Bronte V, Nitti D. Nitric oxide, a double edged sword in cancer biology: searching for therapeutic opportunities. Med Res Rev. 2007;27(3):317-352. doi:10.1002/(ISSN)1098-1128

85. McKinlay AC, Xiao B, Wragg DS, Wheatley PS, Megson IL, Morris RE. Exceptional behavior over the whole adsorption-storagedelivery cycle for $\mathrm{NO}$ in porous metal organic frameworks. $J \mathrm{Am}$ Chem Soc. 2008;130(31):10440-10444. doi:10.1021/ja801997r

86. Bayat Mokhtari R, Homayouni TS, Baluch N, et al. Combination therapy in combating cancer. Oncotarget. 2017;8(23):38022-38043. doi:10.18632/oncotarget.16723

87. Lan G, Ni K, Xu Z, Veroneau SS, Song Y, Lin W. Nanoscale metal-organic framework overcomes hypoxia for photodynamic therapy primed cancer immunotherapy. J Am Chem Soc. 2018;140 (17):5670-5673. doi:10.1021/jacs.8b01072

88. Lu K, He C, Guo N, et al. Chlorin-based nanoscale metal-organic framework systemically rejects colorectal cancers via synergistic photodynamic therapy and checkpoint blockade immunotherapy. $J$ Am Chem Soc. 2016;138(38):12502-12510. doi:10.1021/jacs. $6 \mathrm{~b} 06663$

89. Zeng JY, Zou MZ, Zhang M, et al. pi-extended benzoporphyrin-based metal-organic framework for inhibition of tumor metastasis. ACS Nano. 2018;12(5):4630-4640. doi:10.10 21/acsnano.8b01186

90. Song W, Kuang J, Li CX, et al. Enhanced immunotherapy based on photodynamic therapy for both primary and lung metastasis tumor eradication. ACS Nano. 2018;12(2):1978-1989. doi:10.1021/acsnano.7b09112

91. Ni K, Lan G, Chan C, et al. Nanoscale metal-organic frameworks enhance radiotherapy to potentiate checkpoint blockade immunotherapy. Nat Commun. 2018;9(1):2351.

92. $\mathrm{Lu} \mathrm{K}, \mathrm{He} \mathrm{C}$, Guo $\mathrm{N}$, et al. Low-dose X-ray radiotherapyradiodynamic therapy via nanoscale metal-organic frameworks enhances checkpoint blockade immunotherapy. Nat Biomed Eng. 2018;2(8):600-610. doi:10.1038/s41551-018-0203-4
93. Li Y, Di Z, Gao J, et al. Heterodimers made of upconversion nanoparticles and metal-organic frameworks. $\mathrm{J}$ Am Chem Soc. 2017;139(39):13804-13810. doi:10.1021/jacs.7b07302

94. Rengaraj A, Puthiaraj P, Heo NS, et al. Porous NH2-MIL-125 as an efficient nano-platform for drug delivery, imaging, and ROS therapy utilized low-intensity visible light exposure system. Colloids Surf B Biointerfaces. 2017;160:1-10. doi:10.1016/j. colsurfb.2017.09.011

95. He Z, Dai Y, Li X, et al. Hybrid nanomedicine fabricated from photosensitizer-terminated metal-organic framework nanoparticles for photodynamic therapy and hypoxia-activated cascade chemotherapy. Small. 2019;15(4):e1804131. doi:10.1002/ smll.201804131

96. He J, Dong J, Hu Y, Li G, Hu Y. Design of Raman tag-bridged core-shell Au@Cu3(BTC)2 nanoparticles for Raman imaging and synergistic chemo-photothermal therapy. Nanoscale. 2019;11 (13):6089-6100. doi:10.1039/C9NR00041K

97. Zeng JY, Zhang MK, Peng MY, Gong D, Zhang XZ Porphyrinic metal-organic frameworks coated gold nanorods as a versatile nanoplatform for combined photodynamic: photothermal: chemotherapy of tumor. Adv Funct Mater. 2017; 201705451:1-13.

98. Xu J, Wang XF, Chen $\mathrm{P}$, et al. RNA interference in moths: mechanisms, applications, and progress. Genes (Basel). 2016;7 (10):88. doi:10.3390/genes7100088

99. Xiong XB, Lavasanifar A. Traceable multifunctional micellar nanocarriers for cancer-targeted co-delivery of MDR-1 siRNA and doxorubicin. ACS Nano. 2011;5(6):5202-5213. doi:10.1021/ nn2013707

100. Shahzad MM, Lopez-Berestein G, Sood AK. Novel strategies for reversing platinum resistance. Drug Resist Updat. 2009;12 (6):148-152. doi:10.1016/j.drup.2009.09.001

101. Yellepeddi VK, Vangara KK, Kumar A, Palakurthi S. Comparative evaluation of small-molecule chemosensitizers in reversal of cisplatin resistance in ovarian cancer cells. Anticancer Res. 2012;32(9):3651-3658.

102. Wang H, Zhang J, Yu H. Elemental selenium at nano size possesses lower toxicity without compromising the fundamental effect on selenoenzymes: comparison with selenomethionine in mice. Free Radic Biol Med. 2007;42(10):1524-1533. doi:10.1016/j. freeradbiomed.2007.02.013

103. Levina A, Mitra A, Lay PA. Recent developments in ruthenium anticancer drugs. Metallomics. 2009;1(6):458-470. doi:10.1039/ b904071d

104. Hsu HW, Wall NR, Hsueh CT, et al. Combination antiangiogenic therapy and radiation in head and neck cancers. Oral Oncol. 2014;50(1):19-26. doi:10.1016/j.oraloncology.2013. 10.003

105. Iwamoto $\mathrm{Y}$, Ishii $\mathrm{K}$, Kanda $\mathrm{H}$, et al. Combination treatment with naftopidil increases the efficacy of radiotherapy in PC-3 human prostate cancer cells. J Cancer Res Clin Oncol. 2017;143 (6):933-939. doi:10.1007/s00432-017-2367-9

International Journal of Nanomedicine

Dovepress

\section{Publish your work in this journal}

The International Journal of Nanomedicine is an international, peerreviewed journal focusing on the application of nanotechnology in diagnostics, therapeutics, and drug delivery systems throughout the biomedical field. This journal is indexed on PubMed Central, MedLine, CAS, SciSearch ${ }^{\mathbb{B}}$, Current Contents ${ }^{\mathbb{B}} /$ Clinical Medicine,

Journal Citation Reports/Science Edition, EMBase, Scopus and the Elsevier Bibliographic databases. The manuscript management system is completely online and includes a very quick and fair peer-review system, which is all easy to use. Visit http://www.dovepress.com/ testimonials.php to read real quotes from published authors.

Submit your manuscript here: https://www.dovepress.com/international-journal-of-nanomedicine-journal 